\title{
Heterogeneity of narrowing in normal and asthmatic airways measured by HRCT
}

\author{
G.G. King*,§,f , J.D. Carroll${ }^{\S, f}$, N.L. Müller ${ }^{\#}$, K.P. Whittall ${ }^{\mp}$, M. Gao ${ }^{+}$, Y. Nakano*, P.D. Paré*
}

Heterogeneity of narrowing in normal and asthmatic airways measured by HRCT. G. G. King, J.D. Carroll, N.L.Müller, K.P. Whittall, M. Gao, Y. Nakano, P.D. Paré. (C) ERS Journals Ltd 2004.

ABSTRACT: Asthmatic airway narrowing is heterogeneous and contributes to airway hyperresponsiveness. The present study compared heterogeneity of narrowing during methacholine challenge in asthmatics and normal subjects using high-resolution computed tomography (HRCT).

The current authors defined heterogeneity as variability in narrowing greater than the repeatability of measurement. Airways of $<\mathbf{2} \mathbf{~ m m}$ diameter were compared with larger airways from baseline and postmethacholine HRCT of the right lower lung in 13 normals (seven had repeat baseline scans) and seven asthmatics. The coefficient of repeatability was calculated from repeat scans (RepAi) and was compared with heterogeneity of narrowing measured by the variability in narrowing from pre versus postmethacholine scans (Var $\Delta \mathbf{A i})$.

Forced expiratory volume in one second decreased $27 \pm 6 \%$ and $24 \pm 8 \%$ in normals and asthmatics, respectively. Airways $>2 \mathrm{~mm}$ narrowed more heterogeneously in asthmatics (Var $\Delta \mathrm{A} i= \pm 0.85 \mathrm{~mm}$ ) compared with normals $(\operatorname{Var} \Delta \mathrm{A} i= \pm 0.67 \mathrm{~mm}$ ), with both being greater than the measure of repeatability $(\operatorname{RepA} i= \pm 0.16 \mathrm{~mm})$. Small airway narrowing was not heterogeneous in asthmatics (Var $\Delta \mathrm{A} i= \pm 0.59 \mathrm{~mm}$ ) or normals $\left(\operatorname{Var} \Delta_{\mathrm{Ai}}= \pm 0.53 \mathrm{~mm}\right)$ compared with repeatability $(\operatorname{Rep} A \mathrm{i}=0.51 \mathrm{~mm})$.

It is possible to study heterogeneity of airway narrowing in small and large airways using high resolution computed tomography. Airway narrowing is heterogeneous in the large airways of asthmatics and normals, being greater in asthmatics.

Eur Respir J 2004; 24: 211-218.
*University of British Columbia, James Hogg iCAPTURE Centre for Cardiovascular and Pulmonary Research, St. Paul's Hospital, ${ }^{\#}$ Dept of Radiology and Thoracic Imaging Group, Vancouver Hospital, "Dept of Radiology, UBC Hospital, ${ }^{+}$Centre for Health Evaluation and Outcome Sciences, St. Paul's Hospital, Vancouver, Canada. ${ }^{\text {Woolcock }}$ Institute of Medical Research, University of Sydney 2006, and Cooperative Research Centre for Asthma, Sydney, Australia.

Correspondence: G.G. King, Woolcock Institute of Medical Research, University of Sydney 2006, Sydney, Australia.

Fax: 61299066391

E-mail: ggk@woolcock.org.au

Keywords: Airway narrowing, asthma, heterogeneity, quantitative high resolution computed tomography

Received: April 302003

Accepted after revision: April 162004

This work was supported, in part, by an operating grant from the Canadian Institutes of Health Research. G.G. King was supported by a MRC/CLA postdoctoral fellowship \#9611J9N-1003-46453, an Astra/MRC/PMAC Canada Fellowship and AstraZeneca ALF grant-in-Aid.
Airway hyperresponsiveness (AHR), characterised by increased sensitivity and maximal narrowing in response to nonspecific stimuli, is an important feature of asthma and other airway diseases. Many factors could contribute to AHR, however, it has been suggested that heterogeneity of airway narrowing, in and of itself, could be an important contributor $[1,2]$.

Results from studies of inhaled gas radioisotopes [3] have shown the development of heterogenous airway closure and increased ventilation/perfusion mismatch after bronchoconsticting stimuli, especially in asthmatic subjects [4-6]. These findings are consistent with narrowing or closure of the large airways ( $\geqslant 2 \mathrm{~mm}$ diameter) and are concordant with the results of high-resolution computed tomography (HRCT) studies of human airway narrowing [7-9]. Although narrowing has been measured in large airways by direct imaging, the evidence for heterogeneous narrowing has been indirect (i.e. heterogeneous ventilation). Therefore, the level at which heterogeneity occurs is unknown. In contrast, HRCT offers the potential for direct in vivo visualisation of human airways and a comparison of narrowing between airways of different size. Results of a HRCT study of canine airways suggest that airways narrow

For editorial comments see page 193. heterogeneously after the administration of airway smooth muscle (ASM) agonists either by aerosol or intravenously [10].

Heterogeneity of airway narrowing can be measured by the SD of the change in airway lumen area (Ai), as was done in modelling studies $[1,2]$. However, when measuring heterogeneity of narrowing, the results can only be interpreted in relation to the inherent variability in the measurements of $\mathrm{Ai}$. If measurements of $\mathrm{Ai}$ are poorly repeatable (i.e. $\mathrm{SD}$ of repeated measurements is large), then any heterogeneity of narrowing that is small relative to this repeatability will be obscured by the inaccuracies of measurement. The corollary is that even if airway narrowing is homogeneous, narrowing could appear to be heterogeneous if measurements are poorly repeatable. It is only when the SD of narrowing is compared with the measurement repeatability that heterogeneity can be meaningfully interpreted.

In the present study, the authors examined the hypothesis that airways narrow heterogeneously after methacholine inhalation in normal and asthmatic subjects and that heterogeneity is greater in asthmatics. $\mathrm{Ai}$ was measured from HRCT scans using a previously validated algorithm in normal and asthmatic subjects. To determine the repeatability of measurement, RepAi were performed without inducing bronchoconstriction. To measure heterogeneity of narrowing, 
the variability of the change in $\mathrm{Ai}$ between pre and postmethacholine scans was measured.

\section{Methods}

\section{Research plan}

Subjects were tested on two separate, nonconsecutive days The first day was at the lung function laboratory where the dose of methacholine that would be administered prior to the computed tomography (CT) scan was determined, and the second day was in the CT scanning suite. The lung function laboratory study was always completed first to determine the dose of methacholine that was to be given prior to CT scanning, with the time between challenges being 1-7 days. The repeatability of the measurement of $\mathrm{Ai}$ from repeat HRCT scans in seven of 13 normal male subjects was assessed. The magnitude and variability of airway narrowing was measured from HRCT images obtained before and after methacholine challenge in 10 of the 13 normal subjects, and seven asthmatic subjects. HRCT studies were performed at the Depts of Radiology, Vancouver Hospital, Vancouver, Canada and the Royal Prince Alfred Hospital, Sydney, Australia. All subjects gave written informed consent to participate in this study, which was approved by the Human Ethics Review Committees of St. Paul's Hospital and University of British Columbia, Canada, and Central Area Health Service, Australia.

\section{Subjects}

Altogether, 10 nonasthmatic and four asthmatic male subjects were recruited from staff of the University of British Columbia i-CAPTURE Center (table 1 and 2, subjects 1-10, 14-17), and three normal and three asthmatic male subjects were recruited from staff and patients of the Woolcock Institute of Medical Research Australia (table 1 and 2, subjects 11-13, 18-20). Spirometry and methacholine challenges were initially performed in the laboratory with the subjects supine. The baseline forced expiratory volume in one second, forced vital capacity and inspiratory capacity (IC) were measured and expressed as per cent predicted based on the equations of CRAPO et al. [11]. Normal subjects had no chronic respiratory symptoms, disease diagnosis or long-term medication use. Asthma was diagnosed according to the American Thoracic Society guidelines. All subjects were current non or exsmokers of $<10$ pack-yrs.

\section{Lung function and methacholine challenge test}

Normal subjects (subjects 1-10) underwent high-dose methacholine challenge tests in which doubling concentrations of methacholine were administered, from $1 \mathrm{mg} \cdot \mathrm{mL}^{-1}$ to a possible maximal concentration of $256 \mathrm{mg} \cdot \mathrm{mL}^{-1}$ [12]. The known bronchodilating effect of deep inspiration led to its prohibition during methacholine challenge, and only partial flow volume manoeuvres were performed after each dose (maximal exhalation from end tidal inspiration to residual volume), from which the partial FEV1/FVC ratio (Rpartial) was calculated [13]. The challenge was stopped if the Rpartial decreased to $\leqslant 0.55$, the subjects' requested stopping or when the maximal concentration had been administered. Full spirometry was then performed and the IC was measured from the first manoeuvre. The $R$ partial was used as an indication of airway narrowing and to guard against excessive airway narrowing for safety reasons during the challenge. However, FEV1 was used as the primary measure of airway narrowing.

In Canada, asthmatic subjects underwent methacholine challenges starting at a concentration of $0.25 \mathrm{mg} \cdot \mathrm{mL}^{-1}$ followed by doubling concentrations using a Hudson Bennett Twin Jet Nebuliser (Hudson Bennett, Temecula, CA, USA) and 2 min of tidal breathing via a face mask according to the protocol of JUNIPER et al. [14]. In Australia, asthmatic subjects underwent methacholine challenges using the rapid method [15] using DeVilbiss Number 45 hand-held nebulisers (DeVilbiss, Heston, UK) in cumulative doubling doses from $0.03-8 \mu \mathrm{mol}$. The challenge was otherwise identical to that described above for the normal subjects.

\section{HRCT scanning}

HRCT was performed using a CT9800 Whole Body Scanner (General Electric (GE), Milwaukee, WI, Canada) in Canada and a CTI Whole Body Scanner (GE) in Sydney. Both of these single-matrix scanners were used in helical mode

Table 1.-Lung function data in normal subjects

\begin{tabular}{|c|c|c|c|c|c|c|c|c|}
\hline $\begin{array}{l}\text { Subject } \\
\text { number }\end{array}$ & Age yrs & $\begin{array}{l}\text { FEV1 \% } \\
\text { pred }\end{array}$ & FEV1/FVC & $\begin{array}{c}\text { Decrease in FEV1 } \\
\% \text { baseline }\end{array}$ & $\begin{array}{l}\text { IC postchallenge } \\
\text { in laboratory }\end{array}$ & $\begin{array}{l}\text { IC postchallenge } \\
\text { at HRCT }\end{array}$ & $\begin{array}{l}\text { IC postchallenge } \\
\text { HRCT } \% \text { baseline }\end{array}$ & $\begin{array}{c}\text { Methacholine } \\
\text { concentration } \\
\mathrm{mg} \cdot \mathrm{mL}^{-1}\end{array}$ \\
\hline 1 & 27 & 83 & 0.89 & 30 & 2.14 & 2.20 & 67 & 8 \\
\hline 2 & 33 & 73 & 0.82 & 50 & 1.82 & 1.45 & 62 & 256 \\
\hline 3 & 31 & 82 & 0.78 & 21 & 3.05 & 2.65 & 79 & 8 \\
\hline 4 & 29 & 94 & 0.83 & 66 & 2.45 & 2.05 & 51 & 16 \\
\hline 5 & 35 & 91 & 0.78 & 7 & 3.61 & 3.54 & 103 & 2 \\
\hline 6 & 25 & 92 & 0.81 & 37 & 4.00 & 3.75 & 88 & 4 \\
\hline 7 & 32 & 98 & 0.87 & 20 & 3.21 & 3.10 & 77 & 256 \\
\hline 8 & 41 & 79 & 0.77 & 13 & 4.00 & 2.85 & 90 & 32 \\
\hline 9 & 34 & 84 & 0.83 & 9 & 3.60 & 3.52 & 86 & 256 \\
\hline 10 & 39 & 88 & 0.81 & 19 & 3.85 & UA & 107 & 2 \\
\hline 11 & 26 & 72 & 0.72 & & & & & \\
\hline 12 & 22 & 85 & 0.85 & & & & & \\
\hline \multirow[t]{2}{*}{13} & 34 & 83 & 0.83 & & & & & \\
\hline & $31 \pm 2$ & $85 \pm 2$ & $0.81 \pm 0.01$ & $27 \pm 6$ & $3.17 \pm 0.25$ & $2.79 \pm 0.26$ & $81 \pm 5$ & $20^{\#}$ \\
\hline
\end{tabular}

Data are presented as $n$ or mean \pm SEM. IC postchallenge ( $\%$ baseline) is mean of the postchallenge IC in the CT suite expressed as a percentage of the prechallenge IC measured in the laboratory challenge. FEV1 \% pred: forced expiratory volume in one second as a percentage of the predicted values; FVC: forced vital capacity; IC: inspiratory capacity; HRCT: high-resolution computed tomography; UA: unavailable. ${ }^{\#}$ : Geometric mean; ${ }^{\top}$ : same IC used for the baseline HRCT. 
Table 2. - Lung function data in asthmatic subjects

\begin{tabular}{|c|c|c|c|c|c|c|c|c|}
\hline $\begin{array}{l}\text { Subject } \\
\text { number }\end{array}$ & Age yrs & $\begin{array}{l}\text { FEV1 \% } \\
\text { pred }\end{array}$ & FEV1/FVC & $\begin{array}{c}\text { Decrease in FEV1 } \\
\% \text { baseline }\end{array}$ & $\begin{array}{l}\text { IC postchallenge } \\
\text { in laboratory }\end{array}$ & $\begin{array}{c}\text { IC } \\
\text { postchallenge } \\
\text { at HRCT }\end{array}$ & $\begin{array}{l}\text { IC postchallenge } \\
\text { HRCT } \% \text { baseline }\end{array}$ & $\begin{array}{c}\text { Methacholine } \\
\text { concentration } \\
\mathrm{mg} \cdot \mathrm{mL}^{-1}\end{array}$ \\
\hline 14 & 44 & 44 & 0.52 & 17 & 2.04 & 1.05 & 39 & 0.25 \\
\hline 15 & 28 & 79 & 0.76 & 36 & 3.37 & 3.30 & 89 & 1 \\
\hline 16 & 26 & 65 & 0.77 & 14 & 2.40 & 3.05 & 95 & 2 \\
\hline $17^{\bullet}$ & 28 & 94 & 0.72 & & 3.25 & & & 4 \\
\hline 18 & 33 & 68 & 0.53 & 27 & 3.30 & 3.40 & 72 & $3.05^{\#}$ \\
\hline 19 & 47 & 53 & 0.56 & 16 & 2.70 & 2.60 & 93 & $0.40^{\#}$ \\
\hline \multirow[t]{2}{*}{20} & 38 & 77 & 0.67 & 34 & 2.60 & 2.60 & 63 & $0.40^{\#}$ \\
\hline & $35 \pm 3$ & $69 \pm 6$ & $0.65 \pm 0.04$ & $24 \pm 8$ & $2.81 \pm 0.19$ & $2.67 \pm 0.69$ & $75 \pm 17$ & \\
\hline
\end{tabular}

Data are presented as $\mathrm{n}$ or mean \pm SEM. IC postchallenge (\% baseline) is mean of the postchallenge IC in the CT suite expressed as a percentage of the prechallenge IC measured in the laboratory challenge. FEV1 \% pred: forced expiratory volume in one second as a percentage of the predicted values; FVC: forced vital capacity; IC: inspiratory capacity; HRCT: high-resolution computed tomography. \#: methacholine dose ( $\mu$ mol); ${ }^{\uparrow}$ : subject was unable to perform technically satisfactory spirometry post CT scan.

with 1-mm collimation, a pitch of 1 , a 40 -cm field of view (FOV), $120 \mathrm{kV}$ peak and $200 \mathrm{~mA}$. At baseline, $2 \mathrm{~cm}$ axial length of lung caudad to the inferior pulmonary ligament was scanned during a single breath-hold, which yielded 20 contiguous images of $1-\mathrm{mm}$ thickness (i.e. no gap between scans). A repeat baseline scan was obtained $\sim 5$ min later in subjects 2, 5, 9-13 (table 1) during another breath-hold manoeuvre. The final dose of methacholine that had been given in the laboratory was readministered to subjects $1-10$ and 14-20 after which a 1-cm axial distance of lung, that was within the baseline HRCT field, was rescanned.

The known relationship between airway calibre and lung volume led the present study to standardise this for both the baseline and postmethacholine HRCT. The current authors did this by controlling lung volume during the baseline scan using a water-seal spirometer in the following manner. With the CT scanner tube already rotating, subjects inhaled to total lung capacity from the water-seal spirometer, then exhaled the predetermined IC slowly and were prompted to breath-hold when the predetermined lung volume had been reached, at which time scanning commenced. The predetermined IC was that measured at the completion of the methacholine challenge on day 1 . For postmethacholine scans, subjects were instructed to breath-hold at end expiration (i.e. at functional residual capacity) and to signal this by waving their hand, at which time scanning commenced. All scans were, therefore, performed during breath-hold and the degree of hyperinflation (i.e. IC) was assumed to be similar for methacholine challenges done at the time of the HRCT to that after methacholine in the lung function laboratory. The comparison of the ICs after the methacholine challenges in the laboratory and CT suite (tables 1 and 2) showed this to be a satisfactory method.

The CT image data were reconstructed using a high-spatial frequency algorithm (GE "bone algorithm") using a $20 \mathrm{~cm}$ reconstruction FOV and a $512 \times 512$ matrix (pixel size $0.39 \times 0.39 \mathrm{~mm}=0.15 \mathrm{~mm}^{2}$ ) focused on the right lung. The same airways were compared in pre and postmethacholine scans by matching the branching patterns of the pulmonary vessels [7]. All airways that could be successfully matched and in which lumen measurements could be made (fig. 1) using the authors' semi-automated computer algorithm (see below), were used in the analysis.

\section{Image analyses}

Measurements of Ai were made from HRCT image data using a computer algorithm; Computed Tomographic Airway Morphometry that had been previously validated using inflation fixed porcine lungs [16]. Ai was defined by a threshold attenuation value of $\leqslant 300 \mathrm{~g} \cdot \mathrm{L}^{-1}$ and corrected for both airway size and angle of orientation in relation to the central axis of the scanner, calculated from the $\mathrm{x}, \mathrm{y}$ and $\mathrm{z}$ displacements of the lumen centroids of slices above and below the slice being analysed. In effect, measurements were derived from cross-sectioned, rather than oblique, images.

For analyses, all $\mathrm{Ai}$ measurements were square root transformed $(\sqrt{\mathrm{Ai}})$ because $\mathrm{Ai}$ is a squared function of airway diameter. Mean airway narrowing for each subject was measured as the slope of the regression between baseline $\sqrt{\mathrm{Ai}}$ versus postmethacholine $\sqrt{\mathrm{Ai}}$, for which there was a linear relationship in all subjects. Mean narrowing was also calculated as the mean per cent change in $\mathrm{Ai}$, for airways grouped by their baseline internal diameter $(<1 \mathrm{~mm}, 1-2 \mathrm{~mm}$, etc.), calculated from the Ai. Pre and postmethacholine Ai's were compared using ANOVA and Duncan's post hoc test.

\section{Data analyses}

The repeatability of $\mathrm{Ai}$ measurements (RepAi) were calculated from the repeat $\sqrt{ } \mathrm{Ai}$ measurements made from the two baseline scans, by the methods of BLAND and Altman [17], where:

$$
\operatorname{Rep}_{\mathrm{Ai}}=\sqrt{ } 2 \times \mathrm{t} 0.05 \times \mathrm{Sw}
$$

$\mathrm{Sw}$ is the SD of the differences derived from repeated measures analysis of variance and $\mathrm{t} 0.05$ is the critical $\mathrm{t}$-value corresponding to the sample size. The variability in the

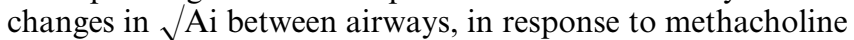
inhalation (Var $\Delta \mathrm{Ai}$ ), were calculated from the Bland and Altman plots of the differences in pre and post methacholine $\sqrt{ } \mathrm{Ai}$ versus the baseline $\sqrt{ } \mathrm{Ai}[17]$. Hence:

$$
\operatorname{Var}_{\Delta \mathrm{Ai}}=\mathrm{t}_{0.05} \times \mathrm{SD} \text { of the differences }
$$

All other data are presented as mean \pm SEM. Heterogeneous airway narrowing was defined to be present when the variability in airway narrowing was greater than the variability due to measurement noise for airways grouped by asthmatic versus normal and by small versus large. In such a comparison, if repeatability were size dependent, variability could appear to be greater, if by chance, larger airways were sampled. Therefore, the present study confirmed that RepAi was independent of airway size by visual inspection of the scatter plots of SD of the difference in $\sqrt{ } \mathrm{Ai}$ measurements of each airway versus baseline $\sqrt{ } \mathrm{Ai}$ and by the Kendall rank correlation tau statistic $(=0.11, p=0.09)$ [17]. Finally, it was assumed that the errors in measurement were the same for both RepAi and postmethacholine scans. This was likely since the quality of images (absence of motion artefact) and 

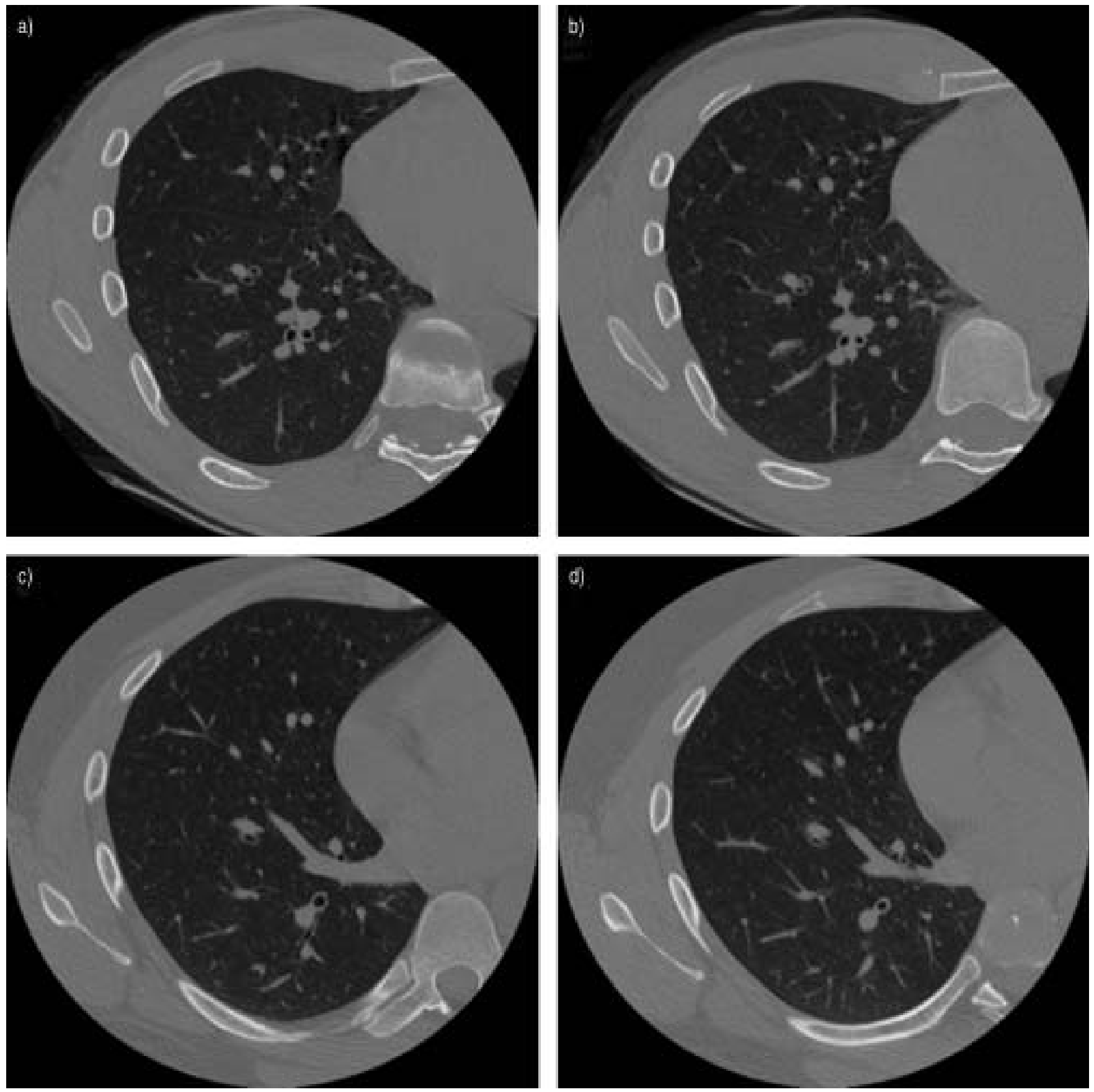

Fig. 1.- Targeted reconstructions of the right lung in a normal subject (number 5) a) pre and b) postmethacholine inhalation, and an asthmatic subject (number 16) c) pre and d) postmethacholine inhalation.

matching of CT slices were comparable for both the RepAi and the postmethacholine scans.

\section{Results}

Table 1 shows the individual data for age and lung function in the normal subjects. The mean FEV1\% predicted was $85 \pm 2 \%$ in normal subjects and $<80 \%$ in two subjects. This low mean value is probably due to the subjects' supine position causing a small decrease in lung volume [18], which was supported by the FEV1/FVC ratio being normal in all but one subject. The mean baseline $R$ partial was $0.75 \pm 0.02$. The FEV 1 and FVC decreased by $27 \pm 6 \%$ and $12 \pm 4 \%$, respectively at the end of the methacholine challenge. Table 2 shows the individual data for age and lung function in the asthmatic subjects. The mean FEV1\% pred was $69 \pm 6$. The FEV1 and FVC decreased by $24 \pm 8 \%$ and $16 \pm 7 \%$, respectively.

Table 3 shows the degree of airway narrowing in all subjects as measured by the slope of the linear regression between baseline $\sqrt{ } \mathrm{Ai}$ versus postmethacholine $\sqrt{\mathrm{Ai}}$. There was no difference in mean slopes between asthmatic and normal subjects $(0.91 \pm 0.05$ and $0.80 \pm 0.04$, respectively, $\mathrm{p}>0.05)$. There were no significant relationships between the slope of baseline $\sqrt{\mathrm{Ai}}$ versus postmethacholine $\sqrt{\mathrm{Ai}}$, and changes in FEV1, IC or Rpartial of subjects. The decrease in FEV1 after methacholine was related to the degree of hyperinflation measured by the per cent change in IC in 
Table 3. - Airway narrowing in normal and asthmatic subjects

\begin{tabular}{|c|c|c|c|c|c|c|}
\hline Subject number & Slope & $\mathrm{R}^{2}$ & $\operatorname{Var} \Delta \mathrm{Ai} \mathrm{mm}$ & Number of airways & RepAi mm & Number of airways \\
\hline 1 & 0.71 & 0.92 & 0.66 & 15 & & \\
\hline 2 & 0.82 & 0.78 & 0.65 & 16 & 0.37 & 10 \\
\hline 3 & 0.89 & 0.86 & 0.66 & 14 & & \\
\hline 4 & 0.78 & 0.77 & 0.40 & 25 & & \\
\hline 5 & 0.99 & 0.89 & 0.27 & 11 & 0.39 & 24 \\
\hline 6 & 0.94 & 0.84 & 0.36 & 22 & & \\
\hline 7 & 0.89 & 0.74 & 0.83 & 7 & & \\
\hline 8 & 0.63 & 0.70 & 0.60 & 9 & & \\
\hline 9 & 0.60 & 0.46 & 0.70 & 11 & 0.58 & 30 \\
\hline 10 & 0.77 & 0.83 & 0.50 & 14 & 0.47 & 11 \\
\hline 11 & & & & & 0.34 & 11 \\
\hline 12 & & & & & 0.42 & 13 \\
\hline 13 & & & & & 0.16 & 11 \\
\hline 14 & 0.74 & 1.00 & 0.39 & 4 & & \\
\hline 15 & 0.95 & 0.84 & 0.55 & 21 & & \\
\hline 16 & 0.74 & 0.92 & 0.64 & 21 & & \\
\hline 17 & 0.91 & 0.84 & 0.27 & 13 & & \\
\hline 18 & 1.04 & 0.94 & 0.83 & 14 & & \\
\hline 19 & 0.96 & 0.88 & 0.57 & 13 & & \\
\hline 20 & 1.05 & 0.92 & 0.82 & 13 & & \\
\hline
\end{tabular}

The magnitude of airway narrowing that occurred following methacholine challenge, measured by the slope of $\sqrt{ }$ airway lumen area $(\sqrt{ }$ Ai) (baseline) versus $\sqrt{\mathrm{Ai}}$ (post). Var $\Delta \mathrm{Ai}$ : heterogeneity of narrowing measured by the variability in narrowing from pre versus postmethacholine scans. RepAi: the coefficient of repeatability of Ai measurements calculated from repeat scans.

normals and asthmatics combined $\left(\mathrm{R}^{2}=0.29, \mathrm{p}=0.04\right)$. There was no relationship between the mean percentage change in Ai and change in FEV1 in asthmatics and normals combined.
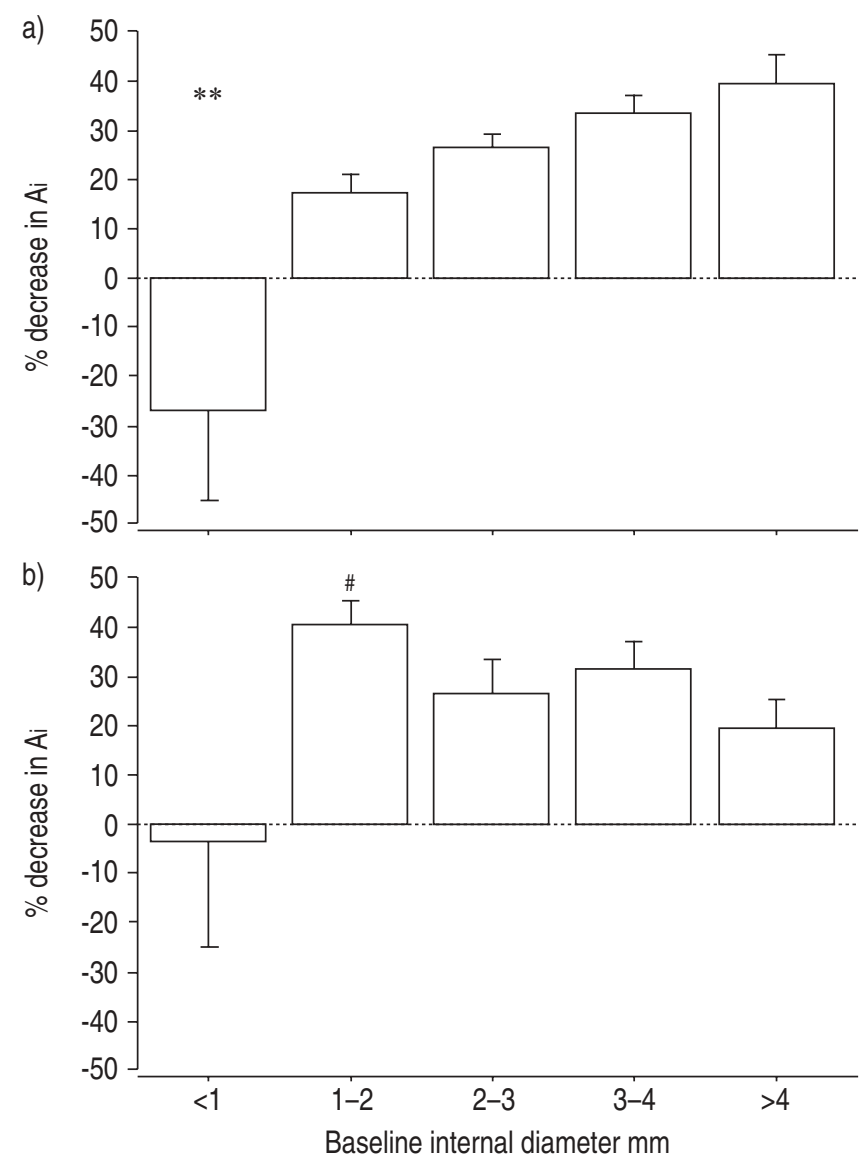

Fig. 2.-The mean percentage decrease in airway lumen area (Ai) according to the baseline airway size in a) 10 normal and b) 7 asthmatic subjects. **: $\mathrm{p}<0.01$ versus airways $>1 \mathrm{~mm}$ diameter; ${ }^{\#}: \mathrm{p}=0.02$ versus airways $<1 \mathrm{~mm}$ initial diameter. Error bars represent SEM.
The data in figure $2 \mathrm{a}$ shows the percentage changes in $\mathrm{Ai}$ between pre and postmethacholine scans, by initial airway size, in 144 normal airways. Airways were categorised as $<1 \mathrm{~mm} \quad(\mathrm{n}=7), 1-2 \mathrm{~mm} \quad(\mathrm{n}=68), 2-3 \mathrm{~mm} \quad(\mathrm{n}=47), 3-4 \mathrm{~mm}$ $(\mathrm{n}=17)$ and $>4 \mathrm{~mm}(\mathrm{n}=5)$. The changes in 99 asthmatic airways are similarly shown in figure $2 \mathrm{~b}$. Airways were also categorised as $<1 \mathrm{~mm} \quad(\mathrm{n}=18), 1-2 \mathrm{~mm} \quad(\mathrm{n}=33), \quad 2-3 \mathrm{~mm}$ $(n=22), 3-4 \mathrm{~mm}(n=14)$ and $>4 \mathrm{~mm}(n=12)$. There was no significant change in mean Ai of airways that had an initial internal diameter $<1 \mathrm{~mm}$ at baseline $(p>0.05)$ in both asthmatic and normal subjects but significant narrowing occurred in larger airways in both asthmatic and normal subjects $(\mathrm{p}<0.05)$. In normals, narrowing in airways $<1 \mathrm{~mm}$ in diameter was less than narrowing in the other groups. In asthmatic subjects, mean airway narrowing in airways $1-2 \mathrm{~mm}$ in diameter was greater than the mean narrowing in airways $<1 \mathrm{~mm}(\mathrm{p}=0.02)$ and $>4 \mathrm{~mm}(\mathrm{p}=0.03)$ diameter.

Figure $3 \mathrm{a}$ is a Bland and Altman plot of repeatability of $\sqrt{ } \mathrm{Ai}$ measurements and the scatter of data points shows their repeatability (a total of 110 airways from seven subjects). The repeatability coefficient (RepAi) was $\pm 0.48 \mathrm{~mm}$. Figure $3 \mathrm{~b}$ is a Bland and Altman plot of the differences in baseline $\sqrt{ } \mathrm{Ai}$ and postmethacholine $\sqrt{\mathrm{Ai}}$, versus baseline $\sqrt{\mathrm{Ai}}$ in normal subjects (a total of 144 airways from 10 subjects) from which Var $\Delta \mathrm{Ai}$ was $0.66 \mathrm{~mm}$. Similarly, figure $3 \mathrm{c}$ shows the degree of heterogeneity of airway narrowing within asthmatic subjects (a total of 99 airways from seven subjects) from which $\operatorname{Var} \Delta \mathrm{Ai}$ was $0.74 \mathrm{~mm}$. The RepAi and $\operatorname{Var} \Delta \mathrm{Ai}$ for individuals are shown in Table 3.

Although the repeatability of absolute measurements was comparable across airway sizes, the relative errors were very size dependent. Figure 4 shows the repeatability of $\mathrm{Ai}$ measurements, when expressed as a percentage of baseline $\mathrm{Ai}$. The poor repeatability of $\mathrm{Ai}$ measurements in the smaller airways, due to limitations in resolution, indicates that it is more difficult to measure airway narrowing as a percentage change in baseline $\mathrm{Ai}$, in these airways. Furthermore, this limitation could also have led to "data censoring" and underestimation of heterogeneity (data censoring could occur if airways that narrowed a lot could not be identified postbronchoconstriction leading to overrepresentation of 

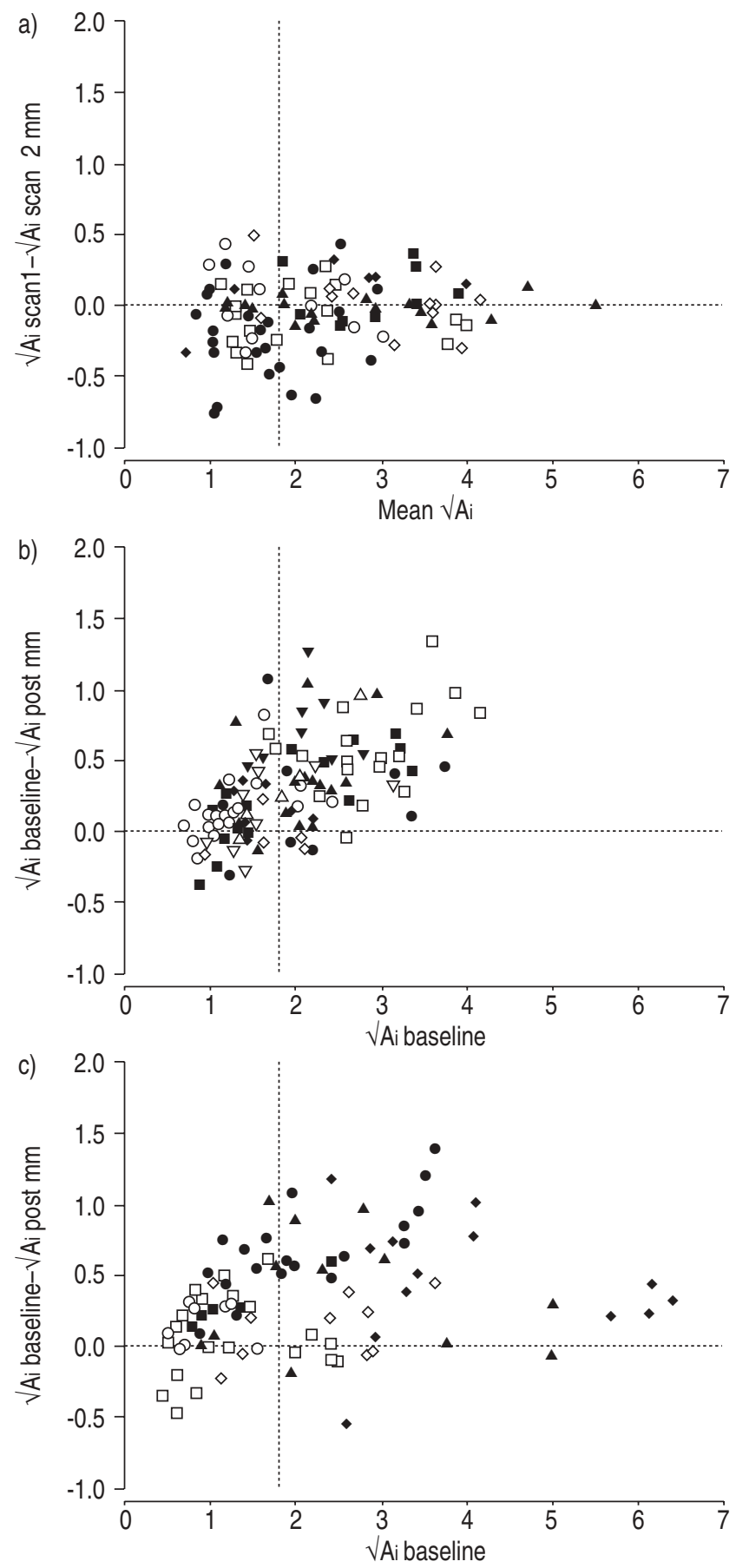

Fig. 3. - a) The repeatability of airway lumen area (Ai) measurements shown by Bland and Altman plots of the repeated $\sqrt{ }$ Ai measurements in subjects $2: \mathbf{\square} ; 5: \square ; 9: 0 ; 10: \bigcirc ; 11: \diamond ; 12: \diamond$; and 13: $\mathbf{\Delta}$, b) heterogeneity of narrowing of normal airways shown in Bland and Altman plots of: the difference between $\sqrt{ } \mathrm{Ai}$ at baseline ( $\sqrt{ } \mathrm{Ai}$ baseline) and $\sqrt{ } \mathrm{Ai}$ after methacholine challenge ( $\sqrt{ } \mathrm{Ai}$ post) versus $\sqrt{ }$ Ai baseline in subjects 1: $\mathbf{\square} ; 2: \square ; 3: \bullet ; 4: \bigcirc ; 5: \diamond ; 6: \diamond ; 7: \boldsymbol{\Delta}$; 8: $\triangle ; 9: \boldsymbol{\nabla}$; and $10: \nabla$, and c) heterogeneity of narrowing of asthmatic airways in subjects 14: $\mathbf{\square}$; 15: $\square$; 16: ๑; 17: $\bigcirc$; 18: $\bullet$; 19: $\diamond$; and 20: $\boldsymbol{\Lambda}$. The vertical dotted line demarcates the $\sqrt{\mathrm{Ai}}$ baseline for airways of $2 \mathrm{~mm}$ internal diameter.

airways that narrowed less). Consequently, the present study also compared variability by airway size; initial airway diameter $<2 \mathrm{~mm}$ and $\geqslant 2 \mathrm{~mm}$. Narrowing of small airways $(<2 \mathrm{~mm}$ diameter) was not heterogeneous since repeatability ( $\operatorname{RepAi}=0.51 \mathrm{~mm})$ was similar to variability of airway

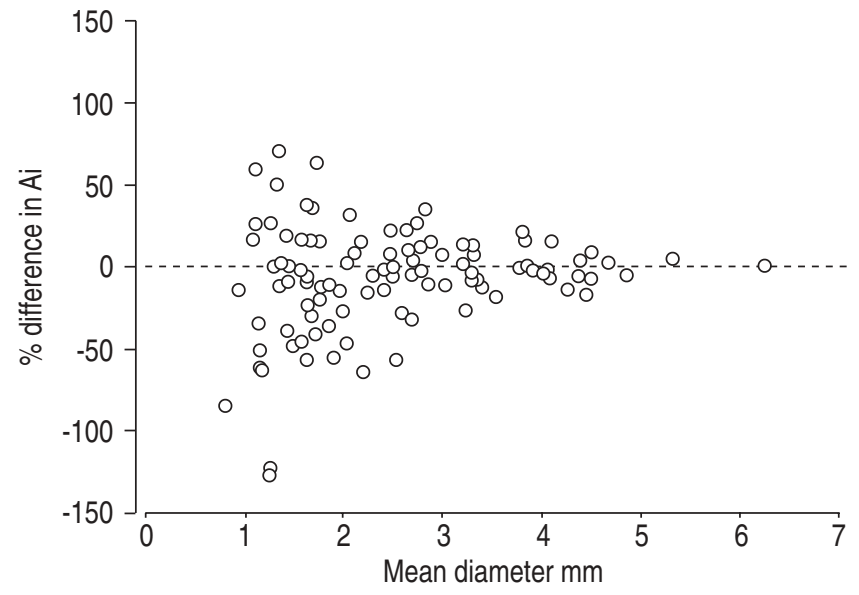

Fig. 4.-Repeatability of airway lumen area (Ai) measurements plotted as the percentage difference in $\mathrm{Ai}$ versus the mean $\mathrm{Ai}$.

narrowing in normals ( $\operatorname{Var} \Delta \mathrm{Ai}=0.53 \mathrm{~mm}$ ) and asthmatics (Var $\Delta \mathrm{Ai}=0.59 \mathrm{~mm})$. In airways $\geqslant 2 \mathrm{~mm}$ diameter, airway narrowing was heterogeneous compared with repeatability $(\operatorname{RepAi}=0.16 \mathrm{~mm})$ in both normals (Var $\Delta \mathrm{Ai}=0.67 \mathrm{~mm}$, $\mathrm{p}<0.01$ ) and asthmatics ( $\operatorname{Var} \Delta \mathrm{Ai}=0.85 \mathrm{~mm}$ ) with heterogeneity of airway narrowing being greater in asthmatics than normals. The number of airways measured to determine repeatability was greatest in subject nine who also had the worst repeatability. Excluding data on subject nine did not alter any of the findings of heterogeneity.

\section{Discussion}

The present study assessed the reproducibility of measurements of $\mathrm{Ai}$ in normal subjects and compared these data with the heterogeneity of airway narrowing following methacholine challenge. Since any technique of measuring airway dimensions has inherent variability, the current authors reasoned that what is measured as heterogeneity of narrowing, is the sum of both measurement variability and true heterogeneity. The reproducibility of $\mathrm{Ai}$ measurement was found to be inversely related to airway size when measured by per cent change in Ai. Hence, it is difficult to detect either narrowing or heterogeneity of narrowing in airways $<1 \mathrm{~mm}$ diameter but the detection of airway narrowing in airways of 1-2 $\mathrm{mm}$ diameter was possible. The large airways of normals and asthmatics were found to narrow heterogeneously but this was not the case for the small airways, when compared with repeatability measurements. The present study also found that the degree of heterogeneity of narrowing in asthmatics was greater than in normals.

Lung volume had to be controlled because of the known relationship between lung volume and airway calibre [19] by using a spirometer and asking the nonbronchoconstricted subjects to exhale a standardised volume from full lung inflation; this volume was equal to the postbronchoconstriction IC after the final inhalation of methacoholine on day 1. Variability in measurements of Ai in repeated HRCT scans could have arisen from small changes in the position of the subjects between scans, from small errors in the matching of airways, from the inherent limitations in the resolution of HRCT for detecting the inner edge of the airways and from differences in the lung volume at which the scans were acquired due to differences in lung volume at full inflation. In addition, spontaneous variability of regional ASM tone could also have contributed to the variability. Airway calibre has 
been found to vary by as much as two-fold over several weeks in an HRCT study of dogs [20], while spontaneous variability in calibre of normal airways has also been suggested to occur based on the presence of intrabreath variation in respiratory system impedance [21].

The finding of greater narrowing of larger airways after methacholine inhalation in the present study is similar to the finding of OKAZAWA et al. [7] who measured airway narrowing in six normal and six asthmatic subjects using HRCT. Smaller airways may indeed narrow less, however, another possibility is data censoring due to the limitations of resolution of HRCT. Lumen measurements from baseline scans were excluded from the analysis if $\mathrm{Ai}$ was unmeasurable in postmethacholine scans, even though many were probably either closed or narrowed to below the limits of HRCT detection. This would result in lesser degrees of apparent airway narrowing in small airways. The limits of HRCT resolution are clearly evident in the data in figure 4, which shows repeatability calculated as a percentage of baseline airway diameter. The repeatability coefficient for airways of $<2 \mathrm{~mm}$ diameter was $85 \%$ compared with $37 \%$ for larger airways. It was, therefore, unlikely that the current study would be able to measure airway narrowing in airways of $\leqslant 1 \mathrm{~mm}$ diameter since their Ai was $<0.79 \mathrm{~mm}^{2}$, which represents only $\sim 5$ pixels.

Another limitation on the measurements of heterogeneity was the volume of lung that it was possible to scan in the present study. The number of airways examined and the number of scans per individual, were limited due to restrictions in radiation exposure. The current work scanned the lower lung zones because this region has more airways which run in an axial direction and analysed only airways in the right lung because of cardiac motion artefact in the left lung. In addition, scanning the lung bases maximised the number of airways that could be measured in each subject, which is an important consideration when measuring variation in narrowing within subjects. There is no theoretical reason or published data to suggest heterogeneity should be limited to a single lung or region. Both the number of airways that were sampled and the repeatability of Ai measurements determined the power with which it was possible to detect heterogeneous airway narrowing in the present study. Since only a mean of $14 \pm 2$ airways per subject were studied out of thousands of airways, this limited sampling meant that the current study was unable to adequately describe the true degree of heterogeneity.

The presented results are in contrast with the report of BROWN et al. [10], who found substantial heterogeneity of airway narrowing in dogs using HRCT. Possible explanations include species differences and/or differences in scanning technique. Maximal shortening of canine ASM [22] is approximately twice that of human ASM [23], which may permit a greater range of narrowing. Greater shortening of canine ASM has been confirmed in vivo by BROWN AND MITZNER [24] who reported that large airways could narrow by $\sim 90 \%$ after methacholine challenge. Differences in technique include scanning of a larger lung volume in animals since radiation exposure is not a concern, and minimisation of motion artefacts by ventilatory control of the paralysed and mechanically ventilated animals. These differences would tend to reduce measurement variability and reveal real differences in the degree of airway narrowing between airways. Despite the potential advantages of an animal preparation, some of the heterogeneity reported by BROWN et al. [10] could have been due to measurement variability, since they did not report the repeatability of their measurements.

Interestingly, no significant correlation was found between the mean decrease in airway lumen diameter, as measured by HRCT, and physiological measurements of airway narrowing; FEV1 and Rpartial. The partial FEV1/FVC ratio was used in the present study as a measure of airway narrowing, although it was not, in fact, the primary measure of airway narrowing, for which the FEV1 was used. The partial FEV1/FVC ratio has been described by SKLOOT et al. [13] for modified methacholine challenge tests in which deep inspirations were prohibited. It has also been used by BROWN et al. [8] once again to study the effects of prohibition of deep inspiration during modified challenges in five normal subjects using HRCT. They found a relationship between Rpartial and the change in airway lumen area on HRCT. The disparity between the current findings and those of BROWN et al. [8] may have been due to differences in methods of volume standardisation, differences in the magnitude of airway narrowing or differences in airway sizes that were imaged in the current study. Since the measurement of FEV1 requires a deep inspiration, and since it is well documented that deep inspiration can largely reverse airway narrowing in normal subjects $[13,25,26]$, it is not surprising that this measurement did not correlate with HRCT measurements. However, the measurement of Rpartial was made before a deep inspiration and one might have expected it to correlate with the airway dimensions. Alternatively, the small number of airways, and subjects that were sampled in the present work and the interplay of multiple parameters in determining maximal expiratory flow and the ratio of partial FEV1 to partial FVC are probably responsible for the lack of association.

The importance of the presented data is that they are direct measurements of the variability of airway narrowing, whereas all previous data of heterogeneity of airway narrowing in humans were indirect. As such, the magnitude and sites at which heterogeneity occur could only have been inferred. Mathematical modelling of the effects of serial and parallel heterogeneity have allowed interpretations on global measurements of lung function, such as multiple breath nitrogen washout [27] and frequency dependence of resistance [28]. The results of such studies suggest that human airway narrowing is heterogeneous and greater in asthmatics. The current findings of more heterogeneous narrowing in asthmatic airways compared with normal airways also supports findings from the modelling studies of airway resistance [28].

In summary, the present study has documented the repeatability of in vivo measurements of airway lumen area, as measured by high-resolution computed tomography, in normal subjects and found that the constraints of highresolution computed tomography resolution limited the ability to measure airway narrowing and heterogeneity of airway narrowing in very small airways of $<1 \mathrm{~mm}$ internal diameter. Airway narrowing was found to be heterogeneous in large airways in normal and asthmatic subjects, with the degree of heterogeneity being greater in asthmatics. These data also help to set limits on the size of airways that can be reasonably evaluated and the number of airways and subjects that need to be studied in future high-resolution computed tomography experiments of airway narrowing and heterogeneity of airway narrowing. The implications of the current findings are that, to more robustly study the clinical and physiological significance of heterogeneity using airway imaging, methods of measuring airway dimensions must become more reproducible. If and when objective measurements of airway narrowing, using high-resolution computed tomography, come into routine use in clinical practice, it will be necessary to define the repeatability of measurements so that the statistical significance of changes associated with disease or treatment can be determined. Such improvements are likely to arise from multi-matrix scanning technology, which allow faster scanning and less motion artefact, higher resolution detectors and improved three-dimensional segmentation methods that are validated using biological lung standards. 


\begin{abstract}
Acknowledgements. The authors wish to thank D. Shepherd of the Dept of Radiology, Vancouver Hospital for the expertise, help and cheerful disposition during CT scanning.
\end{abstract}

\section{References}

1. Thorpe CW, Bates JH. Effect of stochastic heterogeneity on lung impedance during acute bronchoconstriction: a model analysis. J Appl Physiol 1997; 82: 1616-1625.

2. Lutchen KR, Gillis H. Relationship between heterogeneous changes in airway morphometry and lung resistance and elastance. J Appl Physiol 1997; 83: 1192-1201.

3. Murata K, Itoh $\mathrm{H}$, Senda M, Todo G, Yonekura $\mathrm{Y}$, Torizuka K. Ventilation imaging with positron emission tomography and nitrogen 13. Radiology 1986; 158: 303307.

4. Samee S, Altes T, Powers $\mathrm{P}$, et al. Imaging the lungs in asthmatic patients by using hyperpolarized helium-3 magnetic resonance: assessment of response to methacholine and exercise challenge. J Allergy Clin Immunol 2003; 111: 12051211

5. McCarthy D, Milic-Emili J. Closing volume in asymptomatic asthma. Am Rev Respir Dis 1973; 107: 559-570.

6. King GG, Eberl S, Salome CM, Young IH, Woolcock AJ. Differences in airway closure between normals and asthmatics measured by SPECT and Technegas. Am J Resp Crit Care Med 1998; 158: 1900-1908.

7. Okazawa M, Müller NL, McNamara AE, Child S, Verburgt L, Paré PD. Human airway narrowing measured using high resolution computed tomography. Am J Respir Crit Care Med 1996; 154: 1557-1562.

8. Brown RH, Croisille P, Mudge B, Diemer FB, Permutt S, Togias A. Airway narrowing in healthy humans inhaling methacholine without deep inspirations demonstrated by HRCT. Am J Resp Crit Care Med 2000; 161: 1256-1263.

9. Brown RH, Scichilone N, Mudge B, Diemer FB, Permutt S, Togias A. High-resolution computed tomographic evaluation of airway distensibility and the effects of lung inflation on airway caliber in healthy subjects and individuals with asthma. Am J Respir Crit Care Med 2001; 163: 994-1001.

10. Brown R, Herold C, Hirshman C, Zerhouni E, Mitzner W. Individual airway constrictor response heterogeneity to histamine assessed by high-resolution computed tomography. J Appl Physiol 1993; 74: 2615-2620.

11. Crapo RO, Morris AH, Gardner RM. Reference spirometric values using techniques and equipment that meet ATS recommendations. Am Rev Respir Dis 1981; 123: 659-664.

12. Moore B, Hilliam C, Verburgt L, Wiggs B, Vedal S, Paré P. Shape and position of the complete dose-response curve for inhaled methacholine in normal subjects. Am J Respir Crit Care Med 1996; 154: 642-648.

13. Skloot G, Permutt S, Togias A. Airway hyperresponsiveness in asthma: a problem of limited smooth muscle relaxation J Clin Invest 1995; 96: 2393-2403.

14. Juniper E, Cockcroft D, Hargreave F. Histamine and methacholine challenge test. Tidal breathing method. In: Laboratory procedure and standardization, 2nd edn. Lund, Sweden, Canadian Thoracic Society, 1991.

15. Yan K, Salome CM, Woolcock AJ. Rapid method for measurement of bronchial responsiveness. Thorax 1983; 38: $760-765$.

16. King GG, Müller NL, Whittall KP, Xiang QS, Paré PD. An analysis algorithm for measuring airway lumen and wall areas from HRCT data. Am J Respir Crit Care Med 2000; 161: $574-580$.

17. Bland J, Altman D. Measurement error. BMJ 1996; 313: 744.

18. Shardonofsky FR, Martin JG, Eidelman DH. Effect of body posture on concentration-response curves to inhaled methacholine. Am Rev Res Dis 1992; 145: 750-755.

19. Vincent NJ, Knudson R, Leith DE, Macklem PT, Mead J. Factors influencing pulmonary resistance. J Appl Physiol 1970; 29: 236-243.

20. Brown R, Zerhouni E, Mitzner W. Variability in the size of individual airways over the course of one year. Am J Respir Crit Care Med 1995; 151: 1159-1164.

21. Que C-L, Kenyon CM, Olivenstein R, Macklem PT, Maksym GN. Homeokinesis and short-term variability of human airway caliber. J Appl Physiol 2001; 91: 1131-1141.

22. Okazawa M, Ishida K, Road J, Schellenberg RR, Paré PD In vivo and in vitro correlation of trachealis muscle contraction in dogs. J Appl Physiol 1992; 73: 1486-1493.

23. Ishida K, Paré PD, Hards J, Schellenberg RR. Mechanical properties of human bronchial smooth muscle in vitro. $J \mathrm{Appl}$ Physiol 1992; 73: 1481-1485.

24. Brown RH, Mitzner W. The myth of maximal airway responsiveness in vivo. $J$ Appl Physiol 1998; 85: 2012-2017.

25. Moore BJ, Verburgt L, King GG, Paré PD. The effect of deep inspiration on methacholine dose-response curves in normal subjects. Am J Resp Crit Care Med 1997; 156: 12781281.

26. King GG, Moore BJ, Seow CY, Paré PD. Airway narrowing associated with inhibition of deep inspiration during methacholine inhalation in asthmatics. Am $J$ Respir Crit Care Med 2001; 164: 216-218.

27. Verbanck S, Paiva M. Model simulations of gas mixing and ventilation distribution in the human lung. J Appl Physiol 1990; 69: 2269-2279.

28. Lutchen KR, Hantos Z, Petak F, Adamicza A, Suki B. Airway inhomogeneities contribute to apparent lung tissue mechanics during constriction. J Appl Physiol 1996; 80: $1841-1849$. 